\title{
Model-Based Optimal Control of Window Openings for Thermal Comfort ${ }^{\dagger}$
}

\author{
Kui Weng *, Fanlin Meng and Monjur Mourshed \\ School of Engineering, Cardiff University, Cardiff CF10 3AA, UK; MengF8@cardiff.ac.uk (F.M.); \\ MourshedM@cardiff.ac.uk (M.M.) \\ * Correspondence: WengK@cardiff.ac.uk; Tel.: +44-7594823533 \\ † Presented at the Sustainable Places 2018 (SP 2018), Aix-les Bains, France, 27-29 June 2018. \\ Published: 27 August 2018
}

\begin{abstract}
Passive cooling via natural ventilation through window openings is a low-carbon strategy to minimize cooling demand and to adapt to the rising ambient temperatures due to climate change. However, relying on the manual control of windows by occupants is not always optimal for maintaining indoor thermal comfort. In this study, a model-based approach using dynamic thermal simulation program EnergyPlus is used for the optimal control of window openings to maintain indoor thermal comfort. Based on the day-ahead weather forecast, the window opening schedule for the next $24 \mathrm{~h}$ is optimized through iteration. Results indicate that the proposed optimal control method significantly improves indoor thermal comfort than using some most commonly used manual control and automated control based on hourly set-point and outdoor temperatures.
\end{abstract}

Keywords: window openings; optimal control; thermal comfort; UK dwellings

\section{Introduction}

High indoor temperatures can induce heat-related risk to the health and safety of occupants in the dwellings. Vulnerable group of people such as the elderly people and young children are particularly affected by the excessive heat resulting heat-related illness or death [1]. Over 2000 additional deaths were attributed to the 2003 heat wave in the England and Wales [2]. Climate change and deadly heat waves are of increasing concern to tackle the health challenge of hot weather.

The impact of climate on indoor thermal condition can be described into three distinct ways: (1) heat transmission from the external environment through the building envelope according to its insulation and thermal mass; (2) solar transmission through window opening or glazing; (3) and air ventilation or infiltration through the windows, doors, cracks and holes [3]. Natural ventilation through window opening plays an important role in determining indoor environment and adapting to the impact of the climate change [4]. However, occupants lack an understanding of their ventilation systems, resulting in inadequate ventilation in most European dwellings [5].

The control of natural ventilation is becoming more important in improving indoor air quality and thermal comfort [6]. Conventional control of window openings is manually operated by occupants to open or close the windows at different times of a day [7]. Sorgato et al. [8] presented that automated ventilation control provided more hours of thermal comfort than day-time ventilation and night-time ventilation. However, the automated control only opens windows when indoor temperature is over set-point temperature or not less than the outdoor temperature which has not taken account of the effect of different opening schedules on temperature changes over time. This paper introduces a model-based approach to optimal control of window openings in next $24 \mathrm{~h}$ in a UK terraced house. 


\section{Methodology}

\subsection{Simulation Model}

Simulation model has been developed to monitor the effect of window openings on indoor thermal comfort in a typical UK natural ventilated terraced house. Figure 1a,b illustrates that the case study room (Bed 1) is facing South in the first floor of the building in the Cardiff. The elevations of the building are shown in Figure 1c. The windows are assumed to be closed or opened with the 50\% of the total glazed area, which considers some types of windows have different maximum openable area, e.g., bottom and top hung windows have maximum free opening area of $20 \%$ and $80 \%$ respectively [9]. In addition, the model is simulated using a summer day (15 July) weather as natural ventilation is often applied for cooling in summer in the UK dwellings.

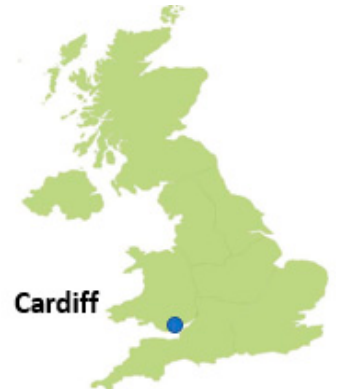

(a)

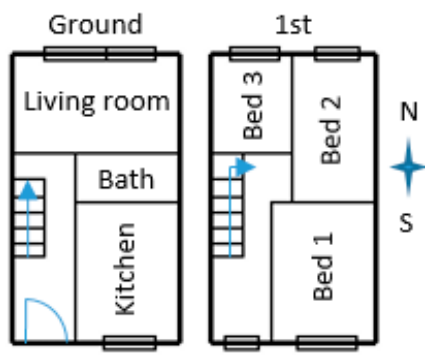

(b)
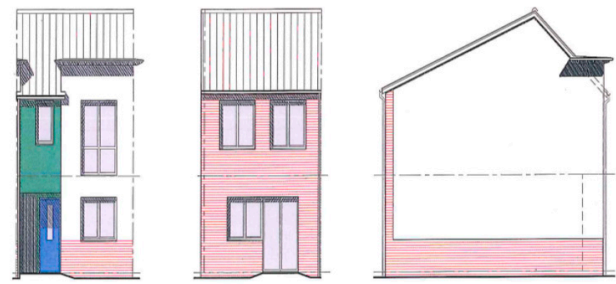

(c)

Figure 1. (a) Location of the house in the UK map; (b) Floor plans; (c) Elevations of the house.

\subsection{Problem Formulation}

In this research, we consider minimizing the gap between the indoor operative $\left(T_{h}\right)$ and thermal comfort temperature at each hour $\left(T_{c}\right)$ where $h \in\{1,2, \ldots H\}$, and $H$ represents the optimization horizon. The decision variables are defined as $A_{h}$; i.e., the window opening area at each hour $h$. Given a window opening schedule, the indoor operative temperature is simulated using EnergyPlus. The cost function $z$ is formulated as:

$$
\min z=\sum_{h=1}^{H}\left(T_{h}-T_{c}\right)^{2}
$$

where $A_{h}$ is equal to $0 \%$ or $50 \%$ of the window area representing the status of the window: closing or opening; $H=24$ represents the optimization horizon; i.e., one day and $T_{c}$ is the neutral or comfort temperature defined in European adaptive thermal comfort standard EN15251. The neutral temperature is the operative temperature that the average person or the largest proportion of a group of people will report as thermally neutral or comfortable.

\subsection{Optimization}

A computer program has been developed to automatically modify the opening schedule in each simulation. From the simulation, the generated hourly indoor operative temperature will then be used to evaluate the cost function. Assume all possible window opening schedules have been simulated and evaluated, an optimal window opening schedule will be found when comparing the objective values. The solution framework is shown in Figure 2. 


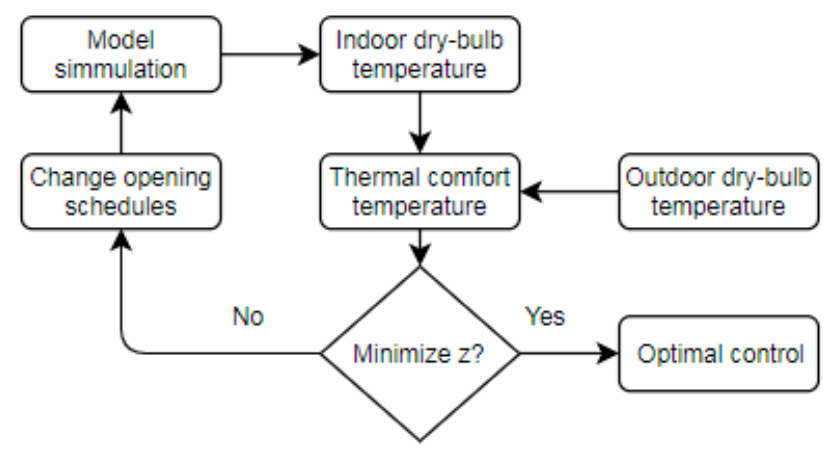

Figure 2. Flow diagram for model-based optimal control of window openings.

Randomly opening or closing windows in each hour in a day can form a total of $2^{24}$ opening schedules. Therefore, the optimization of window openings for next $24 \mathrm{~h}$ can be a computationally resource-intensive problem. As each simulation running requires 20-30 s to finish, it takes decades to have the global optimization of 24-h opening schedule which is time consuming and impractical in hourly control. Instead of 24-h optimization, the strategy is to use four group of with 6-h optimization as $\left(4 \times 2^{6}\right)$ simulation can be completed within an hour.

\section{Results \& Discussions}

Figure 3a presents the indoor operative temperature for different window opening scenarios. The optimal control gives out the best result of indoor operative temperature. Compared with the conventional opening control and automated control, they are closer to the neutral thermal comfort temperature of $22.87^{\circ} \mathrm{C}$. The green line shows that the indoor temperature drops significantly at 11 am and $14 \mathrm{pm}$ when windows are opened for cooling.

As shown in Figure 3a, most often used conventional window openings are also tested. No ventilation and fully ventilation scenarios result in the maximum and minimum indoor operative temperatures. It is found that indoor condition is more sensitive to night ventilation in Cardiff's current climate as the indoor temperature drops significantly when windows opened during the night. Day-time ventilation strategy performs better as windows are closed during the night and no air change would occur through the window ventilation.

Automated opening controls open windows when indoor temperature exceeds the settemperature and outdoor temperature. Compared with the optimal opening control, it underestimates the indoor operative temperature as window openings only occurs when indoor operative temperature overriding the comfort temperature. The reaction to outdoor weather only considers opening or not in each hour. However, optimal control of window opening takes account of next $6 \mathrm{~h}$ global optimization. The 24-h optimal opening schedule is made of four 6-h optimal opening schedules. Therefore, the optimal control performs better than this kind of automated controls. 


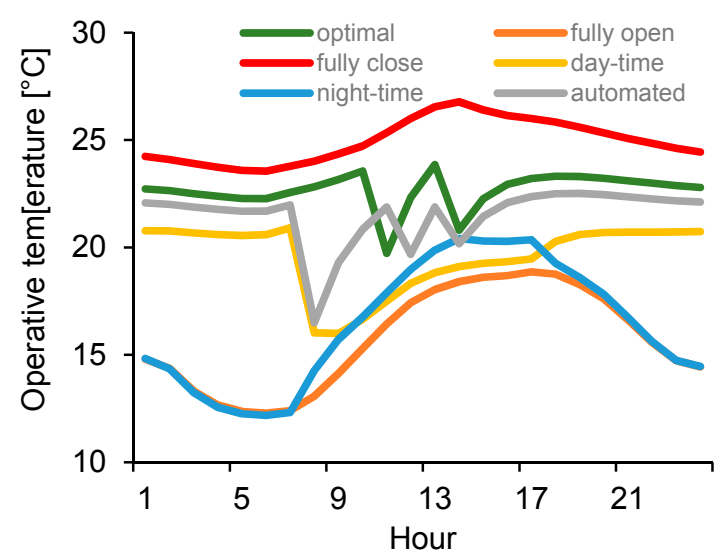

(a)

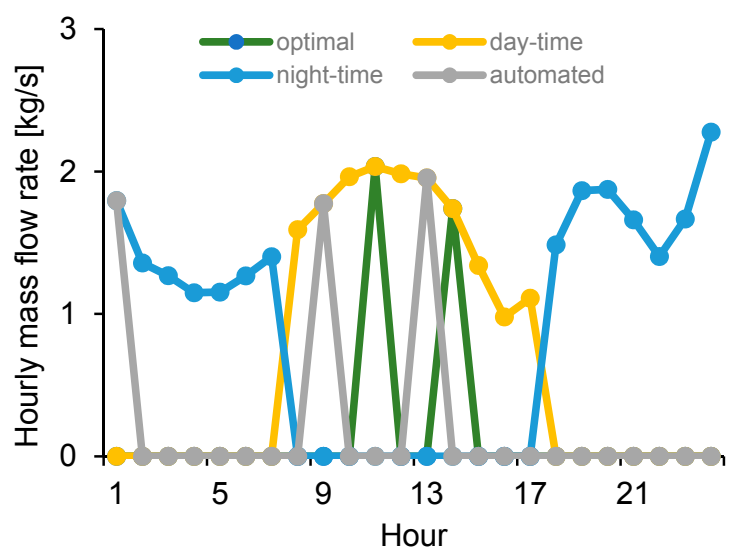

(b)

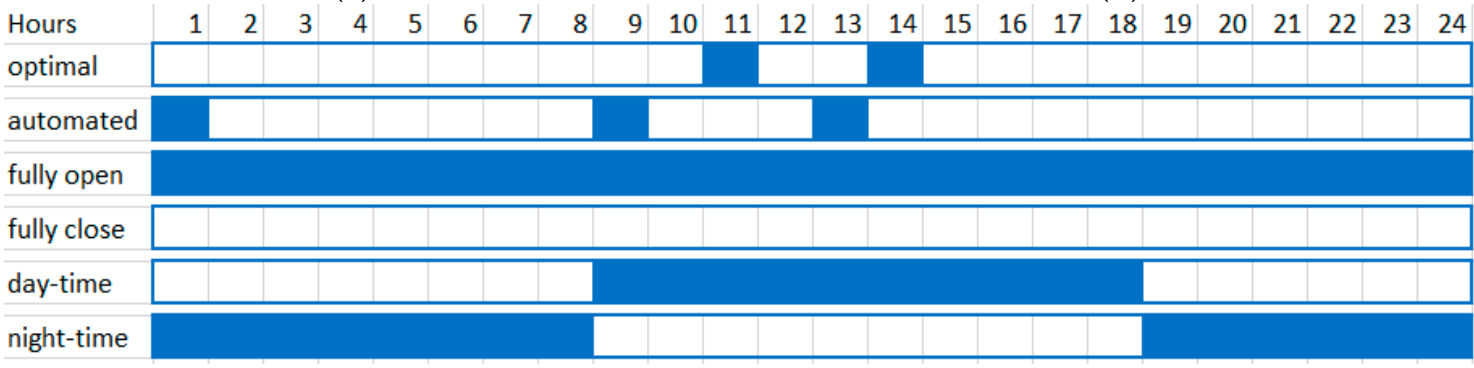

(c)

Figure 3. (a) Indoor operative temperature of each opening scenario; (b) mass flow rate of 4 different opening scenario; (c) Hourly opening schedules (shaded-open, unshaded-close) for all scenarios.

Figure $3 \mathrm{~b}$ illustrates the mass flow rate of each opening for the four different opening scenarios. There is a slight difference in mass flow rate between the optimal and automated control. Figure $3 \mathrm{c}$ presents the detailed opening schedules for all of the opening scenarios. As shown in Figure $3 b, c$, automated control has one more opening hour and windows are opened at 9 am and $13 \mathrm{pm}$. It is because the indoor operative temperatures are over $22.87^{\circ} \mathrm{C}$ in those hours.

\section{Conclusions}

This paper presents a model-based approach for optimal control of window openings to maximize indoor thermal comfort in a UK terraced house. It combines the modelling simulation and computer programming to optimize hourly window opening schedules for next $24 \mathrm{~h}$ with one dayahead local weather forecast.

The proposed optimal control method provides a significant improvement in indoor thermal comfort compared to manual control and automated control strategies. Manual control of window openings for natural ventilation is difficult for maintaining indoor thermal comfort. Although conventional automated control strategy can improve the indoor thermal condition, it actually underestimates the indoor operative temperature due to no global optimization as optimal control approach. Moreover, this approach provides significant insights on deploying actual control systems in real buildings as it gives an optimal next-day hourly window opening schedules within an hour, compared with conventional manual control and automated control.

Due to the limitation of time consuming iteration of simulation, this method has only considered 'open' and 'close' scenarios (50\% and $0 \%$ of the total glazed area) in next $24 \mathrm{~h}$. Future research should consider more opening area of windows and use computational algorithms to improve the optimization accuracy and speed.

Funding: This work was partially funded by the European Commission via H2020 project, TowArds Building rEady for Demand rEsponse (TABEDE) under Grant Agreement No. 766733. 
Conflicts of Interest: The authors declare no conflicts of interest.

\section{References}

1. Hajat, S.; Kovats, R.S.; Lachowycz, K. Heat-related and cold-related deaths in England and Wales: Who is at risk? Occup. Environ. Med. 2007, 64, 93-100.

2. Wright, A.J.; Young, A.N.; Sukumar, N. Dwelling temperatures and comfort during the August 2003 heat wave. Build. Serv. Eng. Res. Technol. 2005, 26, 285-300.

3. Raja, I.A.; Nicol, J.F.; McCartney, K.J.; Humpherys, M.A. Thermal comfort: Use of controls in naturally ventilated buildings. Energy Build. 2001, 33, 235-244.

4. Andersen, R.; Fabi, V.; Toftum, J.; Corgnati, S.P.; Olesen, B.W. Window opening behaviour modelled from measurements in Danish dwellings. Build. Environ. 2013, 69, 101-113.

5. Dimitroulopoulou, C. Ventilation in European dwellings: A review. Build. Environ. 2012, 47, 109-125.

6. Schulze, T.; Eicker, U. Controlled natural ventilation for energy efficient buildings. Energy Build. 2013, 56, 221-232.

7. Roetzel, A.; Tsangrassoulis, A.; Dietrich, U.; Busching, S. A review of occupant control on natural ventilation. Renew. Sustain. Energy Rev. 2010, 14, 1001-1013.

8. Sorgato, M.J.; Melo, A.P.; Lamberts, R. The effect of window opening ventilation control on residential building energy consumption. Energy Build. 2016, 133, 1-13.

9. Openness and Free Area-Inputs. Available online: https://support.sefaira.com/hc/enus/articles/216886426-Openness-and-Free-Area-Inputs (assessed on 20 July 2018).

(C) 2018 by the authors. Licensee MDPI, Basel, Switzerland. This article is an open access article distributed under the terms and conditions of the Creative Commons Attribution (CC BY) license (http://creativecommons.org/licenses/by/4.0/). 